\title{
Diversidad, dominancia y distribución arbórea en Madre de Dios, Perú
}

\author{
Diversity, dominance and distribution of trees in Madre de Dios, Peru
}

Hugo Dueñas Linares ${ }^{1, *}$ y Jorge Santiago Garate Quispe ${ }^{1}$

\begin{abstract}
Resumen
El objetivo del presente estudio fue de realizar un análisis comparativo de la diversidad florística, dominancia y patrones de distribución arbórea $(\mathrm{DAP}>10 \mathrm{~cm}$ ) de 21 parcelas permanentes de 1 ha en bosques de tierras bajas en la región Madre de Dios. Los datos fueron compilados de base de datos como RAINFOR, ForestPlots.net, entre otros. La composición florística fue analizada utilizando las variables de riqueza de especies, géneros y familias. Para el análisis estructural se calcularon los parámetros fitosociológicos de dominancia (área basal $\mathrm{m}^{2} / \mathrm{ha}$ ), abundancia e índice de importancia para cada especie. Para agrupar las parcelas de los sitios de estudio en función a su composición florística se realizaron análisis de conglomerados jerárquicos y un Escalamiento Multidimensional no Métrico para representar en dimensión reducida los patrones de composición florística. Se reportaron 11890 árboles, distribuidos en 83 familias, 335 géneros y 1064 especies, distribuidos en cuatro grupos florísticos, correspondiendo a diferentes tipos de bosques (bosque tierra firme, llanura inundable, pantano estacional y terraza aluvial). Asimismo, mediante una curva de acumulación de especies, utilizando el software StimateS, se proyectó en $\geq 1600$ el número total de especies arbóreas que ocurren en los bosques de tierras bajas del departamento de Madre de Dios; ya que también existen bosques montanos. Los resultados muestran una alta riqueza y diversidad arbórea en Madre de Dios. Con altos valores de diversidad en parcelas de Manu (nor-oeste) y disminuyendo gradualmente en algunas parcelas de Tambopata (sur-este), que están próximas a la frontera con Bolivia.
\end{abstract}

Palabras clave: Parcelas permanentes, diversidad, composición florística; índice de importancia, índice de Jaccard, Madre de Dios

\footnotetext{
${ }^{1}$ Herbario “"'Alwyn Gentry”, Universidad Nacional Amazónica de Madre de Dios, Av. Jorge Chávez 1160, Ciudad Universitaria UNAMAD, Puerto Maldonado17001, Madre de Dios, Perú.

* Autor de Correspondencia: huduli_hugo@yahoo.es
} 


\begin{abstract}
The present study aimed to perform a comparative analysis of floristic diversity, dominance and tree distribution patterns $(\mathrm{DBH}>10 \mathrm{~cm})$ of 21 permanent plots of 1 ha in the region of Madre de Dios. The data were compiled from databases such as RAINFOR, ForestPlots.net, among others. The floristic composition was analyzed using the species, genus and family richness. For the structural analysis, the phytosociological parameters of dominance (basal area $\mathrm{m}^{2} / \mathrm{ha}$ ), abundance and index of importance for each species were calculated. A hierarchical clustering was made to group the plots of the study sites according to the floristic composition. An NMDS were performed to represent the floristic composition patterns in a reduced number of dimensions. A total of 11890 trees were reported, distributed in 83 families, 335 genera and 1064 species, distributed in four floristic groups, corresponding to different types of forests (terra firme forest, floodplain, seasonal swamp and alluvial terrace). Also, using a curve of accumulation of species, using the software StimateS, the total number of tree species that occur in Madre de Dios was projected in $\geq 1600$ species. The results show a high richness and diversity of trees in Madre de Dios, with high values of diversity in plots of Manu (northwest) and decreasing in the plots of Tambopata (southeast), which are close to the border with Bolivia.
\end{abstract}

Key words: Permanent plots, diversity, floristic composition; importance index; Jaccard index, Madre de Dios.

\section{Introducción}

La Amazonia abarca un área de aprox. 6.8 millones $\mathrm{km}^{2}$ situada en la parte norte de América del Sur (Eva et al. 2005). Los bosques húmedos cubren casi el $80 \%$ de la Amazonía (5.5 millones de $\mathrm{km}^{2}$ ) y el restante $20 \%$ está cubierto por bosques secos (1\%), bosques inundados (3\%), hierbas y matorrales (5\%), la vegetación corta o escasa (1\%), así como la agricultura y áreas urbanas (10\%). Los bosques clasificados como los bosques húmedos de tierras bajas amazónicas, se definen como todos los tipos de bosques naturales que crecen en zonas con temperatura media anual por encima de $24^{\circ} \mathrm{C}$, una elevación inferior a 700 msnm, y una precipitación media anual superior a $1400 \mathrm{~mm}$ (Eva et al. 2005), estas selvas tropicales de tierras bajas del Amazonas crecen tanto en terrenos inundados o no inundados y en una variedad de tipos de suelos tropicales, por ejemplo, ferralsoles, los acrisoles, arenosoles y podsoles (Quesada et al. 2011).

Los bosques amazónicos son los más grandes y diversos en los trópicos y mucho del misterio que rodea su ecología, puede remontarse a su esfuerzo por entenderlos a través de inventarios locales pequeños (Pitman et al. 2001). Los bosques tropicales incluyen a las comunidades más diversas de la tierra, los bosques de tierra firme e inundables de Madre de Dios se incluyen a este nivel (Pitman et al. 2001). En el departamento de Madre de Dios han sido reportados altos niveles de diversidad biológica, con sitios singulares teniendo récords mundiales para especies de aves ( $>600$ ) y varios grupos de insectos (por lo menos 1250 mariposas, 150 libélulas) (Pearson 1984; Lamas 1994; Parker et al. 1994). La diversidad de flora es casi tan excepcional como la diversidad de fauna, con más de 1000 especies de árboles registradas en nuestra área de estudio (Phillips et al. 2003). Además, existe la hipótesis de que la diversidad de especies es inducida por la diversidad de hábitats, con un número considerable de especies resistentes que se reemplazan entre los estrechamente encajonados hábitats adyacentes (Erwin 1984; Tuomisto et al. 1995), aunque algunas especies de árboles dominantes sean ubicuas a través del paisaje (Pitman et al. 1999). 
El conocimiento y entendimiento de la riqueza, diversidad de especies y patrones de composición florística a escala local y regional podrían estar determinados por las diferentes variables y condiciones edáficas. Esto permitiría elaborar mapas de distribución de la diversidad y de bosques en las diferentes comunidades. También ayudaría a identificar las opciones de uso adecuado y planificado del territorio, identificación de comunidades de bosques o especies en particular riesgo. Para poder tener un conocimiento más detallado sobre su riqueza y diversidad, y poder caracterizar la variación de las especies a través de los diferentes tipos de bosques es necesario realizar un muestreo amplio y riguroso que implique la aplicación de una metodología integral e intensiva además rápida y eficiente.

El objetivo de la presente investigación fue analizar la diversidad, dominancia, índice de importancia, distribución, composición florística y similitud arbórea de 21 parcelas de 1 ha en la región Madre de Dios, Perú.

\section{Materiales y Métodos}

\section{Área de estudio}

El presente estudio fue realizado en la región Madre de Dios (Perú), en seis diferentes lu-

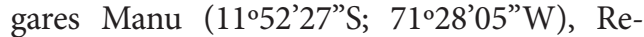
serva ecológica Inkaterra (ITA) (12³0'58"S; $\left.69^{\circ} 04^{\prime} 06^{\prime \prime} \mathrm{W}\right)$, Instituto de Investigación de la Amazonía Peruana (IIAP, 12³9'9"S;

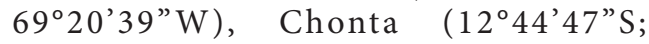
$\left.69^{\circ} 21^{\prime} 26^{\prime \prime} \mathrm{W}\right)$, Tambopata $\left(12^{\circ} 49^{\prime} 32^{\prime \prime} \mathrm{S}\right.$; $\left.69^{\circ} 15^{\prime} 40^{\prime \prime} \mathrm{W}\right)$ y Cuzco Amazónico (12²9'57"S; $69^{\circ} 57^{\prime} 34^{\prime \prime} \mathrm{W}$ ) (Figura 1); abarcando las provincias de Manu y Tambopata. La temperatura promedio anual en Madre de Dios es de $25,4^{\circ} \mathrm{C}$. La precipitación anual es irregular, entre 1500

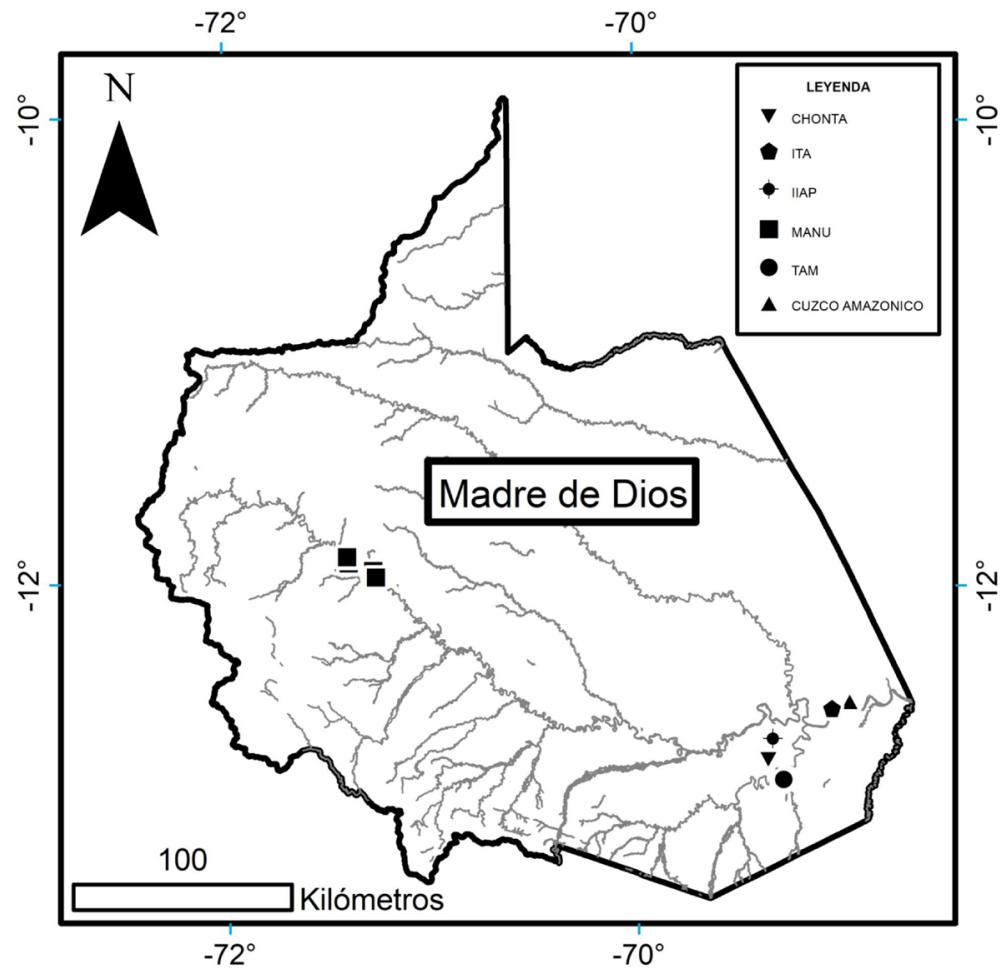

Figura 1. Mapa de ubicación de las 21 parcelas analizadas en Madre de Dios. 
$\mathrm{mm}$ a $2860 \mathrm{~mm}$ (periodo 1980 - 2016) y no están distribuidas regularmente durante el año. En promedio, el $75 \%$ de la precipitación anual está concentrada entre los meses de octubre y abril; y tiene una estación seca entre junio y agosto con un precipitación mensual menor a $100 \mathrm{~mm}$ (Li et al. 2006; Araujo-Murakami et al. 2011).

Para el presente estudio comparativo de la diversidad florística, dominancia y distribución, la información se obtuvo en base a la interpretación de las imágenes de satélites (Imágenes Rapid Eye), exploraciones de campo con colectas de muestras, revisión de colecciones de herbario (depositados en los herbarios USM, MO, CUZ y HAG). Para las parcelas de MANU las identificaciones fueron realizadas por Terbogh, Nuñez y Cornejo. Para las parcelas de Tambopata y Cusco Amazónico, las identificaciones fueron realizadas por Gentry, Nuñez, Phillips, Timaná y Monteagudo. Para las parcelas de ITA, Chonta e IIAP, las identificaciones fueron realizadas por Dueñas, Báez y Oblitas. Las 21 parcelas permanentes de 1 ha se clasificaron en cuatro tipos de bosque (BT$\mathrm{F}=$ Bosque tierra firme, BLLI=Bosque llanura inundable, $\mathrm{BPE}=$ Bosque pantano estacional y $\mathrm{BTA}=$ Bosque terraza aluvial), considerando la clasificación realizada por Encarnación et al. (2008).

\section{Parcelas establecidas}

Se compilaron un conjunto de datos de inventarios de árboles con un diámetro a la altura del pecho mayor o igual a $10 \mathrm{~cm}$ (DAP $\geq 10 \mathrm{~cm}$ ), localizados en diferentes tipos de bosques. Se utilizó la base de datos de ForestPlots.net (https://www.forestplots.net), con los respectivos permisos para utilizar los datos de RAINFOR (Red Amazónica de Inventarios Forestales). Además, se utilizaron parcelas permanentes del proyecto TEAM (http://www. teamnet.work.com), datos proyecto ITA-Tambopata (Dueñas et al. 2012), Proyecto árboles IIAP-Tambopata (Cueva 2015), y Chonta (Baez y Oblitas 2017). Los datos de las parcelas permanentes fueron organizados y compilados en una base de datos en MS Excel; y se organi- zaron en matrices para familias, géneros y especies según parcela. Los nombres científicos, géneros y familias aceptados fueron revisados y corregidos usando la aplicación TNRS (http:// tnrs.iplantcollaborative.org/TNRSapp.html) (Boyle et al. 2013) y la página web especializada del Missouri Botanical Garden (http://tropicos.org). Los géneros y familias se clasificaron de acuerdo al Angiosperm Phylogeny Group (APG IV 2016).

En el Cuadro 1, se describe las características y ubicación de las 21 parcelas evaluadas de 1 ha en cuatro tipos de bosque en el departamento de Madre de Dios. Los datos fueron compilados de la base de datos de RAINFOR (11 parcelas), TEAM (6 parcelas), IIAP (1 parcela), ITA (2 parcelas) y CHONTA (1 parcela).

\section{Técnicas de procesamiento y análisis de datos}

Se realizó la caracterización y comparación de la diversidad y composición florística arbórea entre los sitios evaluados. La composición florística fue analizada utilizando variables de riqueza de especies, riqueza de géneros y familias. Para comparar la diversidad arbórea se calcularon los índices de $\alpha$-Fisher $[S=a \ln (1+1 / a)]$ y Shannon-Weaver $\left[\mathrm{H}^{\prime}=-\sum p_{i} \ln p_{i}\right]$ utilizando el software Paleontological Statistics versión 3.16 (Hammer y Harper 2006). Asimismo, se proyectó el número total de especies arbóreas que ocurren en Madre de Dios, considerando los valores encontrados en las parcelas evaluadas, utilizando el programa StimateS 9.1 (Colwell 2013).

Se realizó un análisis comparativo entre las 21 parcelas de la composición florística en 4 tipos diferentes de bosques, y posteriormente se realiza un análisis comparativo con otras parcelas en otros lugares de la Amazonía peruana.

Por otro lado, se calcularon los parámetros fitosociológicos de dominancia (área basal $\mathrm{m}^{2} / \mathrm{ha}$ ) y abundancia de cada especie para el análisis estructural, y mediante la suma de ambos se obtuvo el índice de importancia (IIE, Ecuación 1) de cada especie y familia (escala de $0-100 \%$ ), por parcela y tipo de bosque. El IIE es una versión simplificada del índice de valor 


\begin{tabular}{|c|c|c|c|c|c|c|c|}
\hline $\mathbf{N}^{\circ}$ & Parcelas & $\begin{array}{l}\text { Tipo de } \\
\text { Bosque }\end{array}$ & $\begin{array}{l}\text { Altitud } \\
\text { (msnm) }\end{array}$ & Latitud & Longitud & Institución & Autor \\
\hline 1 & CUZ-01 & BTA & 190 & $12^{\circ} 30^{\prime} 58^{\prime \prime} \mathrm{S}$ & $69^{\circ} 04^{\prime} 06$ & RAINFOR & Phillips (2011) \\
\hline 2 & CUZ-02 & BTA & 190 & $12^{\circ} 29^{\prime} 57^{\prime \prime S}$ & $69^{\circ} 58^{\prime} 14$ & RAINFOR & Phillips (2011) \\
\hline 3 & CUZ-03 & BTA & 190 & $12^{\circ} 29^{\prime} 58^{\prime \prime} \mathrm{S}$ & $69^{\circ} 57^{\prime} 46$ & RAINFOR & Phillips (2011) \\
\hline 4 & CUZ-04 & $\mathrm{BPE}$ & 190 & $12^{\circ} 29^{\prime} 57^{\prime \prime} \mathrm{S}$ & $69^{\circ} 57^{\prime} 35$ & RAINFOR & Phillips (2011) \\
\hline 5 & TAM-01 & BTF & 205 & $12^{\circ} 50 ’ 39$ ”S & $69^{\circ} 17^{\prime} 18$ & RAINFOR & Phillips (2011) \\
\hline 6 & TAM-02 & BTF & 210 & $12^{\circ} 50 ’ 05 ” \mathrm{~S}$ & $69^{\circ} 17^{\prime} 09$ & RAINFOR & Phillips (2011) \\
\hline 7 & TAM-05 & BTF & 220 & $12^{\circ} 49$ '49”S & $69^{\circ} 16^{\prime} 14$ & RAINFOR & Phillips (2011) \\
\hline 8 & TAM-06 & BTA & 200 & $12^{\circ} 50 ’ 19$ 's & $69^{\circ} 17^{\prime} 45$ & RAINFOR & Phillips (2011) \\
\hline 9 & TAM-07 & $\mathrm{BTF}$ & 225 & $12^{\circ} 49^{\prime} 33^{\prime \prime S}$ & $69^{\circ} 15^{\prime} 40$ & RAINFOR & Phillips (2011) \\
\hline 10 & TAM-08 & BTF & 220 & $12^{\circ} 49^{\prime} 34 ” \mathrm{~S}$ & $69^{\circ} 16^{\prime} 09$ & RAINFOR & Phillips (2011) \\
\hline 11 & TAM-09 & $\mathrm{BTF}$ & 197 & $12^{\circ} 49^{\prime} 53$ 'S & $69^{\circ} 17^{\prime} 04$ & RAINFOR & Phillips (2011) \\
\hline 12 & MANU-01 & BLLI & 345 & $11^{\circ} 53^{\prime} 13^{\prime \prime} \mathrm{S}$ & $71^{\circ} 23^{\prime} 49$ & TEAM & Guerra y Álvarez (2011) \\
\hline 13 & MANU-02 & $\mathrm{BTF}$ & 345 & $11^{\circ} 53 ’ 58^{\prime \prime} \mathrm{S}$ & $71^{\circ} 25^{\prime} 30$ & TEAM & Guerra y Álvarez (2011) \\
\hline 14 & MANU-03 & BTF & 345 & $11^{\circ} 56^{\prime} 14^{\prime \prime} \mathrm{S}$ & $71^{\circ} 16^{\prime} 53$ & TEAM & Álvarez (2011) \\
\hline 15 & MANU-04 & $\mathrm{BTF}$ & 358 & $11^{\circ} 54^{\prime} 17^{\prime \prime} \mathrm{S}$ & $71^{\circ} 24^{\prime} 08$ & TEAM & Luza (2011) \\
\hline 16 & MANU-05 & BLLI & 347 & $11^{\circ} 52^{\prime} 42^{\prime \prime} \mathrm{S}$ & $71^{\circ} 24^{\prime} 31$ & TEAM & Luza (2011) \\
\hline 17 & MANU-06 & BLLI & 339 & $11^{\circ} 57^{\prime} 56^{\prime \prime} \mathrm{S}$ & $71^{\circ} 16^{\prime} 09$ & TEAM & Álvarez (2011) \\
\hline 18 & IIAP & $\mathrm{BTF}$ & 180 & $12^{\circ} 39^{\prime} 21 ’ \mathrm{~S}$ & $69^{\circ} 20^{\prime} 05$ & UNAMAD & Cueva (2011) \\
\hline 19 & ITA I & BTA & 160 & $12^{\circ} 31 ’ 37^{\prime \prime S}$ & $69^{\circ} 02^{\prime} 46$ & UNAMAD & Dueñas (2012) \\
\hline 20 & ITA II & BTA & 160 & $12^{\circ} 31 ' 56^{\prime \prime S}$ & $69^{\circ} 02^{\prime} 45$ & UNAMAD & Dueñas (2012) \\
\hline 21 & CHONTA & BTF & 220 & $12^{\circ} 44^{\prime} 47^{\prime \prime} \mathrm{S}$ & $69^{\circ} 21^{\prime} 26$ & UNAMAD & Oblitas (2015) \\
\hline
\end{tabular}

Cuadro 1. Características de 21 parcelas de 1 ha utilizadas en el presente estudio.

de importancia propuesto por Curtis y McIntosh (1951) sin considerar la frecuencia y tiene similar interpretación que el Índice de Valor de Importancia (IVI) (Lozada 2010).

IIE=Abun (\%)+Dom (\%) (Ecuación 1)

Dónde:

Abun (\%) = Abundancia relativa

Dom $(\%)=$ Dominancia relativa

Para agrupar las parcelas de los sitios de estudio en función a su composición florística, se realizaron análisis de conglomerados jerárquicos usando el paquete Vegan de R (R Core Team 2016; Oksanen et al. 2017). Se utilizó un matriz de distancias de Jaccard, elaborado a partir de una matriz de abundancias trans- formada (raíz cuadrada) para disminuir la influencia de las especies más abundantes en el análisis (Kindt y Coe 2005). Asimismo, como estrategia de agrupamiento se utilizó la media aritmética entre grupos (UPGMA). El número óptimo de conglomerados se definió utilizando el estadístico de Mantel (Borcard et al. 2009) y esta se representó en un dendrograma. Las figuras se realizaron utilizando los paquetes estadísticos Vegan y ggplot2 en entorno de R-studio (R Core Team 2016; Wickham 2015; Oksanen et al. 2017).

Para el análisis de la distribución de la composición florística por tipo de bosque en dimensión reducida (2D), se utilizó el análisis de Escalamiento Multidimensional no Métrico (NMDS), para definir los patrones de la com- 
posición florística de los diferentes tipos de bosques en Madre de Dios. Se obtuvo un Stress de 0.09 , las elipses fueron construidas con un nivel de 0.90 de significancia.

\section{Resultados}

En 21 parcelas evaluadas se reportaron 11 890 árboles (DAP $>10 \mathrm{~cm}$ ), distribuidos en 83 familias, 335 géneros y 1064 especies (Cuadro 2). Se calcula que este número para la flora arbórea se incrementará a más de 1100 especies y morfo especies de árboles para la región de Madre de Dios (Monteagudo com. pers.). Estos datos se corroboran con la revisión de las exsiccata del herbario de USM para el departamento de Madre de Dios (1131 especies, 127 morfo especies, de 3879 colecciones de diferentes autores).

\section{De la abundancia y riqueza de especies}

Los rangos de abundancia varían entre 404 ind/ha, y $684 \mathrm{ind} / \mathrm{ha}$. En las parcelas de Manu se encontró una mayor abundancia (684 ind/ ha, parcela MANU_05), seguida por las parcelas ubicadas en TAM_02 con (677 ind/ha). Por otro lado, las de menor abundancia fueron las parcelas de CHONTA con (404 ind/ha) y la parcela CUZ_01 con (434 ind/ha).

\begin{tabular}{|c|c|c|c|c|c|c|}
\hline Parcelas & $\begin{array}{l}\text { Número de } \\
\text { Individuos }\end{array}$ & Familias & Géneros & Especies & Shannon H & $\alpha$-Fisher \\
\hline CHONTA & 404 & 37 & 91 & 133 & 4.52 & 69.16 \\
\hline CUZ-01 & 434 & 39 & 88 & 130 & 4.17 & 62.9 \\
\hline CUZ-02 & 556 & 43 & 97 & 133 & 3.92 & 55.38 \\
\hline CUZ-03 & 504 & 42 & 96 & 134 & 4.1 & 59.67 \\
\hline CUZ-04 & 602 & 45 & 102 & 157 & 4.34 & 69.04 \\
\hline IIAP & 503 & 40 & 108 & 174 & 4.67 & 94.23 \\
\hline ITA I & 506 & 34 & 80 & 119 & 3.74 & 49.05 \\
\hline ITA II & 570 & 34 & 86 & 135 & 4.17 & 55.88 \\
\hline MANU_01 & 604 & 44 & 94 & 147 & 4.21 & 61.87 \\
\hline MANU_02 & 622 & 47 & 116 & 183 & 4.43 & 87.39 \\
\hline MANU_03 & 597 & 41 & 100 & 140 & 3.67 & 57.6 \\
\hline MANU_04 & 620 & 49 & 135 & 197 & 4.6 & 99.63 \\
\hline MANU_05 & 684 & 44 & 100 & 156 & 4.16 & 63.13 \\
\hline MANU_06 & 622 & 40 & 104 & 147 & 4.19 & 60.77 \\
\hline TAM-01 & 616 & 46 & 109 & 173 & 4.04 & 79.95 \\
\hline TAM-02 & 677 & 40 & 111 & 191 & 4.23 & 88.55 \\
\hline TAM-05 & 532 & 37 & 95 & 162 & 4.51 & 79.34 \\
\hline TAM-06 & 661 & 45 & 112 & 188 & 4.21 & 87.65 \\
\hline TAM-07 & 509 & 42 & 92 & 152 & 4.27 & 73.38 \\
\hline TAM-08 & 515 & 41 & 91 & 142 & 4.33 & 64.8 \\
\hline TAM-09 & 552 & 45 & 116 & 173 & 4.45 & 86.58 \\
\hline TOTAL & 11890 & 83 & 335 & 1064 & - & - \\
\hline Promedio & 566.2 & 41.7 & 101.1 & 155.5 & 4.2 & 71.7 \\
\hline DS & 75.2 & 4 & 12.6 & 22.6 & 0.3 & 14.5 \\
\hline
\end{tabular}

Cuadro 2. Riqueza, Diversidad y composición florística de parcela 1 ha. 
En el Cuadro 2, se observa los valores de riqueza de especies cuyos rangos varían desde 133 especies/ha hasta 197 especies/ha. Las parcelas con mayor riqueza fueron las parcelas de MANU_04 con (197 especies/ha), MANU_02 con (183 especies/ha), seguidas por las parcelas de TAM $(2,6,9)$, y la del IIAP (174 especies/ha). Sin embargo, las parcelas de Cuzco Amazónico (1, 2 y 3) y Chonta tuvieron una menor riqueza de especies.

\section{Del índice de Shannon-Wiener y a-Fisher}

Los rangos de valores del índice de diversidad a-Fisher para las 21 parcelas de 1 ha varían entre 49.05 hasta 99.63. Las parcelas MANU_04 (99.63), MANU_02 (87.39) y TAM_02 (88.5), la parcela IIAP (94.23) tuvieron mayores valores (Cuadro 2). Las parcelas ITA 1 (49.05) y CUZ_02 (55.38) presentaron los valores más bajos del índice de diversidad $\alpha$-Fisher.

El Cuadro 3 muestra los valores promedio del índice de Shannon, con rangos que varían desde 3.97 (Parcela ITA) hasta 4.60 (Parcela CUZ); dichos valores señalan una alta diversidad de especies en los cuatro tipos de bosques.
De igual manera los valores de promedio para el índice de $\alpha$-Fisher, con rangos que varían entre 80.04 (parcela TAM) hasta 81.69 (parcela CHONTA-IIAP), éstos valores indican la presencia de una alta diversidad de especies de árboles en los sitios estudiados.

\section{De la Curva de acumulación de especies}

En la Figura 2, se presenta la curva de acumulación total de especies, donde se aprecia las 1064 especies de árboles ( $>10 \mathrm{~cm}$ DAP) registradas en 21 parcelas de 1 ha, en diferentes tipos de bosque para el departamento de Madre de Dios. Asimismo, se proyectó el número total de especies arbóreas que ocurren en Madre de Dios ( $\geq$ a 1600 especies en los diferentes tipos de bosques) utilizando el programa StimateS 9.1 (Colwell 2013).

\section{De la Diversidad}

Se han registrado en 21 parcelas de 1 ha en el departamento de Madre de Dios, 11890 árboles $\geq 10 \mathrm{~cm}$ DAP, distribuidos en 83 familias, 335 géneros y 1064 especies. Las parcelas MANU_4 estuvieron representadas por 49 familias, 135 géneros y 197 especies, TAM_02

\begin{tabular}{lccccc}
\hline \multicolumn{1}{c}{ Parcelas } & $\begin{array}{c}\text { Altitud } \\
(\mathbf{m s n m})\end{array}$ & Abundancia & Riqueza & Shannon & $\boldsymbol{\alpha}$-Fisher \\
CHONTA-IIAP* & 200 & $404-593$ & $133-174$ & 4.59 & 81.69 \\
CUZ* & 190 & $434-602$ & $130-157$ & 4.6 & 81.7 \\
TAMB* & 211 & $509-677$ & $142-191$ & 4.29 & 80.04 \\
MANU* & 348 & $597-684$ & $147-197$ & 4.49 & 81.14 \\
ITA* & 160 & $506-570$ & $119-135$ & 3.97 & - \\
Yanamono** & 140 & - & 300 & - & - \\
Allpahuayo** & 150 & - & 289 & - & - \\
Chalalan** & 400 & - & 118 & - & - \\
Santa Rosa** & 220 & 531 & 174 & 4.58 & 90.02 \\
Alto Purús** & 298 & $510-678$ & $102-158$ & - & - \\
Tahuamanu** & 260 & $370-500$ & $86-139$ & 3.89 & 50.83 \\
Rio Amigos** & 260 & - & $126-169$ & - & - \\
\hline
\end{tabular}

Cuadro 3. Comparación de Abundancia, Riqueza e Índices de Diversidad. $\left.{ }^{(}\right)$Parcelas analizadas en el presente estudio. ${ }^{* *}$ ) Otras parcelas de la Amazonía. 


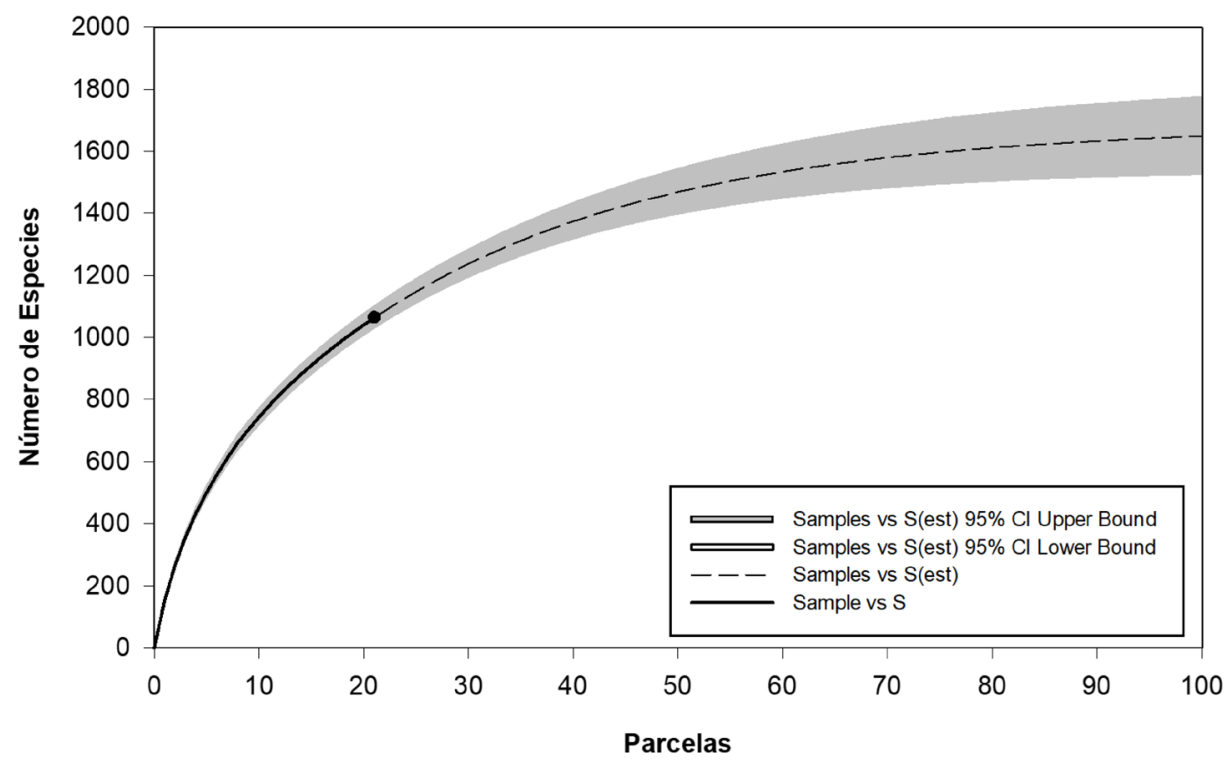

Figura 2. Curva especies área ajustada (línea negra) y estimada (línea punteada), utilizando el programa StimateS para los bosques amazónicos de tierras bajas $(<500 \mathrm{msnm})$ el departamento de Madre de Dios. Debido a que no existen muestras de bosque montano, donde las especies pueden ser diferentes.

con 40 familias, 111 géneros y 191 especies y MANU_02 con 47 familias, 116 géneros y 183 especies son las más representativas. Seguidas de TAM_06 representadas con 45 familias, 112 géneros y 188 especies, la parcela IIAP con 40 familias, 108 géneros y 174 familias y la parcela TAM_09 con 45 familias, 116 géneros y 173 especies. Finalmente, las parcelas que estuvieron menos representadas fueron: la parcela ITA I con 34 familias, 80 géneros y 119 especies, CHONTA con 37 familias, 91 géneros y 133 especies y CUZ_01 con (39 familias, 88 géneros y 130 especies. Los valores más altos en composición florística se pueden atribuir a que estas parcelas se encuentran localizadas en bosque de tierra firme, mientras que los valores más bajos corresponden a parcelas de bosque de terraza aluvial, bosque de pantano inundable y bosque de llanura inundable respectivamente.

\section{Del Índice de Importancia}

En el presente estudio las 5 especies más abundantes fueron Iriartea deltoidea Ruiz \& Pav., Pseudolmedia laevis (Ruiz \& Pav.) J.F.
Macbr., Astrocaryum murumuru Mart., Euterpe precatoria Mart., Quararibea wittii K. Schum \& Ulbr.; con 984, 574, 314, 310 y 293 individuos respectivamente (Cuadro 4).

Las 5 especies más dominantes, considerando el área basal, fueron Iriartea deltoidea, Pseudolmedia laevis, Bertholletia excelsa Bonpl., Poulsenia armata (Miq.) Standl. y Quararibea wittii con $36.6 \mathrm{~m}^{2}, 25.3 \mathrm{~m}^{2}, 10.9 \mathrm{~m}^{2}, 9.8 \mathrm{~m}^{2}$ y $9.5 \mathrm{~m}^{2}$ respectivamente (Cuadro 4). Asimismo, las 5 especies arbóreas con mayor Índice de Importancia fueron: Iriartea deltoidea, Pseudolmedia laevis (4.5\%), Quararibea wittii (2\%), Astrocaryum murumuru (1.9\%) y Euterpe precatoria (1.7 \%) (Cuadro 4).

Por otro lado, las especies con menores valores del índice de importancia (raras) fueron Calatola costaricensis Standl., Pleurothyrium parviflorum Ducke, Tapirira retusa Ducke, Caryodaphnopsis fosteri van de Werff., Gloeospermum sphaerocarpum Triana \& Planch, Sterculia sp.1, Endlicheria bracteata $\mathrm{Mez}$, Dendropanax cuneatus (DC.) Decne. \& 


\begin{tabular}{|c|l|c|c|c|c|c|}
\hline Rank & \multicolumn{1}{|c|}{ Especie } & Individuos & $\begin{array}{c}\text { Abundancia } \\
\text { Relativa } \\
\mathbf{( \% )}\end{array}$ & $\begin{array}{c}\text { Área Basal } \\
\left(\mathbf{m}^{2}\right)\end{array}$ & $\begin{array}{c}\text { Dominancia } \\
\text { Relativa } \\
\mathbf{( \% )}\end{array}$ & $\begin{array}{c}\text { Índice de } \\
\text { importancia } \\
(\mathbf{\%})\end{array}$ \\
\hline 1 & Iriartea deltoidea & 894 & 7.5 & 36.6 & 6.10 & 6.8 \\
\hline 2 & Pseudolmedia laevis & 574 & 4.8 & 25.3 & 4.21 & 4.5 \\
\hline 3 & Quararibea wittii & 293 & 2.5 & 9.5 & 1.58 & 2.0 \\
\hline 4 & Astrocaryum murumuru & 314 & 2.6 & 7.2 & 1.19 & 1.9 \\
\hline 5 & Euterpe precatoria & 310 & 2.6 & 5.2 & 0.87 & 1.7 \\
\hline 6 & Otoba parvifolia & 199 & 1.7 & 9.4 & 1.56 & 1.6 \\
\hline 7 & Pourouma minor & 194 & 1.6 & 8.8 & 1.46 & 1.5 \\
\hline 8 & Leonia glycycarpa & 229 & 1.9 & 6.1 & 1.01 & 1.5 \\
\hline 9 & Pouteria torta & 129 & 1.1 & 9.3 & 1.54 & 1.3 \\
\hline 10 & Rinorea guianensis & 181 & 1.5 & 5.3 & 0.88 & 1.2 \\
\hline 11 & Poulsenia armata & 63 & 0.5 & 9.8 & 1.63 & 1.1 \\
\hline 12 & Iryanthera juruensis & 169 & 1.4 & 3.3 & 0.55 & 1.0 \\
\hline 13 & Bertholletia excelsa & 13 & 0.1 & 10.9 & 1.81 & 1.0 \\
\hline 14 & Attalea phalerata & 94 & 0.8 & 6.3 & 1.05 & 0.9 \\
\hline 15 & Clarisia racemosa & 66 & 0.6 & 7.5 & 1.25 & 0.9 \\
\hline
\end{tabular}

Cuadro 4. Índice de importancia de especies en 21 parcelas de 1 ha en Madre de Dios.

Planch., e Inga umbellifera (Vahl) DC. Ducke; encontrándose 1 individuo de estas especies y poco aporte $\left(<0.01 \mathrm{~m}^{2}\right)$ en área basal en 21 ha (Cuadro 5).

\section{Análisis de conglomerados jerárquicos}

En el dendrograma obtenido, comparando la composición florística arbórea de 21 parcelas de una hectárea en Madre de Dios, se observó la diferenciación significativa en 4 grupos (Figura 3), de acuerdo al estadístico de Mantel, que sugiere una diferenciación en la composición florística en función a la distancia geográfica entre los sitios de estudio, es decir, la similitud $(J$ 's) entre las parcelas está influenciado por la distancia geográfica entre estas $\left(\mathrm{y}=0.303-0.032^{*} \ln (\mathrm{x})\right.$; $r^{2}=0.45, \mathrm{P}<0.001$, Figura 4). Por otro lado, en las parcelas de Manu, se observó una diferenciación en función a tipos de bosque, bosques de tierra firme (Manu 2, Manu 3 y Manu 4) y bosque de llanura inundable (Manu 1, Manu 5 y Manu 6).

Las 5 especies con el mayor índice de importancia en los bosques de tierra de firme de Tambopata (conglomerado 1, Figura 3), IIAP-CHONTA y TAM, fueron Iriartea deltoidea (21\%), Pouroma minor Benoist (7\%), Leonia glycycarpa Ruiz \& Pav. (5\%), Bertholletia excelsa (4.8\%) e Iryanthera juruensis Warb. (4\%). A diferencia de los bosques de terraza aluvial (conglomerado 2, Figura 3), parcela de ITA y CUZ, en las cuales las 5 especies con mayor índice de importancia fueron Pseudolmedia laevis (24.8\%), Quararibea wittii (10.2 \%), Licania brittoniana Fritsch (9.1\%), Guarea macrophylla Vahl (8.5\%) y Sloanea guianensis (Aubl.) Benth. (5.6\%).

Por otro lado, se observó una variación en el índice de importancia entre los tipos de bosque en las parcelas de MANU. Las especies con mayor índice de importancia en los bosques de llanura inundable (conglomerado 3, Figura 3) fueron: Otoba parvifolia (Markgr.) A.H.Gentry (15.2\%), Astrocaryum murumuru (11.9\%), Iriartea deltoidea (8.5\%), Quararibea wittii (8 \%) y Attalea phalerata Mart. ex Spreng. (6\%). Sin embargo, las especies con mayor índice de importancia en Bosques de Tierra Firme (Con- 

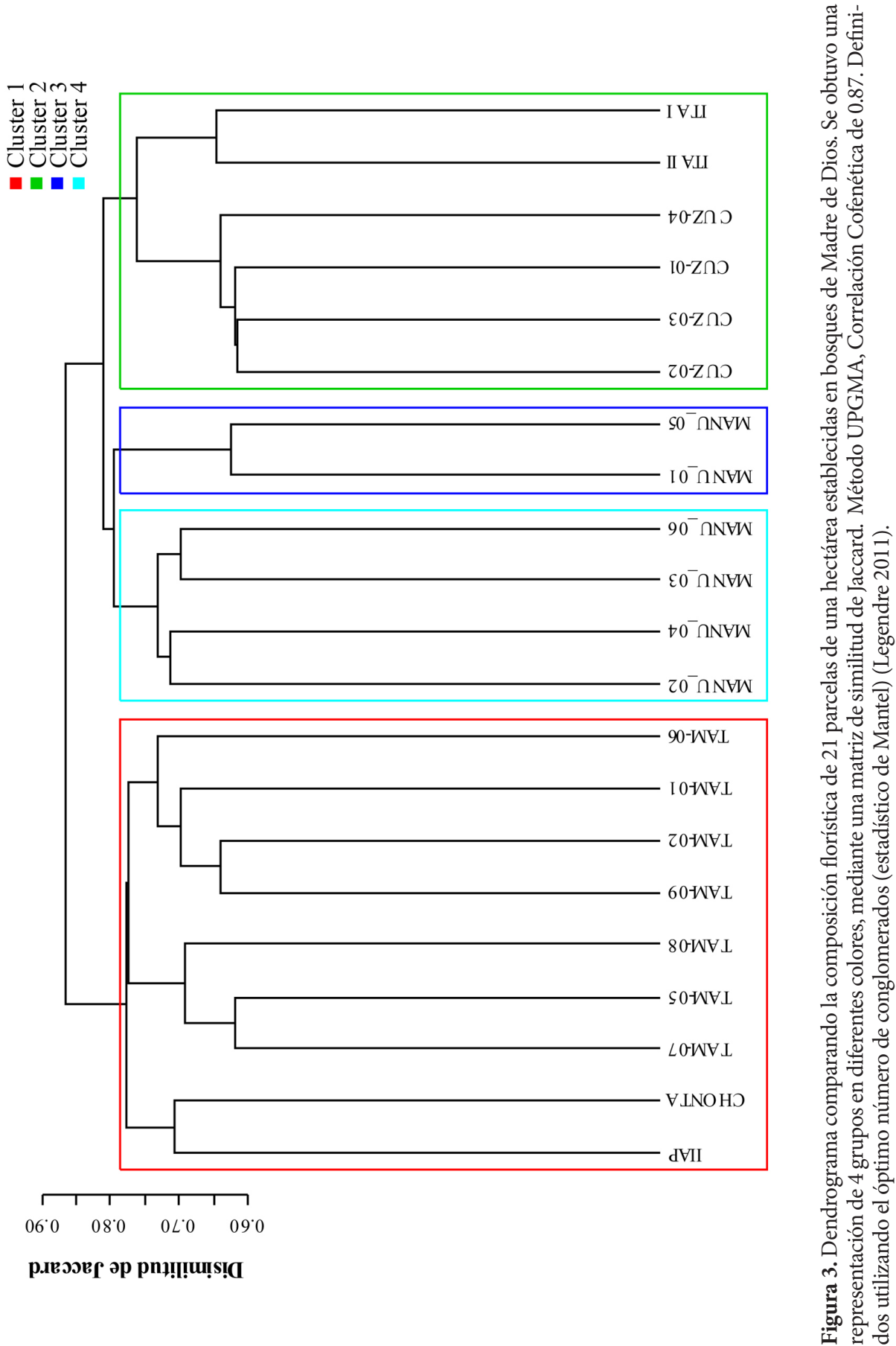

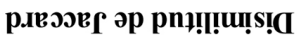




\begin{tabular}{|c|l|c|c|c|}
\hline Rank & \multicolumn{1}{|c|}{ Especies } & Ar $\mathbf{( \% )}$ & Dr (\%) & $\begin{array}{c}\text { Índice de } \\
\text { Importancia }\end{array}$ \\
\hline 1 & Calatola venezuelana & 0.0084 & 0.0013 & 0.0097 \\
\hline 2 & Cassipourea peruviana & 0.0084 & 0.0013 & 0.0097 \\
\hline 3 & Miconia impetiolaris & 0.0084 & 0.0013 & 0.0097 \\
\hline 4 & Pleurothyrium parviflorum & 0.0084 & 0.0013 & 0.0097 \\
\hline 5 & Tapirira retusa & 0.0084 & 0.0013 & 0.0097 \\
\hline 6 & Caryodaphnopsis fosteri & 0.0084 & 0.0013 & 0.0097 \\
\hline 7 & Gloeospermum sphaerocarpum & 0.0084 & 0.0013 & 0.0097 \\
\hline 8 & Salacia gigantea & 0.0084 & 0.0013 & 0.0097 \\
\hline 9 & Sterculia sp.1 & 0.0084 & 0.0013 & 0.0097 \\
\hline 10 & Cupania cinerea & 0.0084 & 0.0014 & 0.0098 \\
\hline 11 & Adenocalymna purpurascens & 0.0084 & 0.0014 & 0.0098 \\
\hline 12 & Endlicheria bracteata & 0.0084 & 0.0014 & 0.0098 \\
\hline 13 & Sorocea hirtella & 0.0084 & 0.0014 & 0.0098 \\
\hline 14 & Dendropanax cuneatus & 0.0084 & 0.0014 & 0.0098 \\
\hline 15 & Inga umbellifera & 0.0084 & 0.0014 & 0.0098 \\
\hline & & & & \\
\hline
\end{tabular}

Cuadro 5. Las especies con menor índice de importancia, 1 individuo en 21 ha y menor aporte en área basal. $\mathrm{Ar}=$ Abundancia relativa, $\mathrm{Dr}=$ dominancia relativa.

glomerado 4, Figura 3) fueron: Rinorea guianensis Aubl. (11.8\%), Iriartea deltoidea (8.7\%), Astrocaryum murumuru (8.5\%), Otoba parvifolia (7.5 \%) y Pseudolmedia laevis (7 \%).

\section{Análisis de ordenación de la composición florística según parcela}

El Análisis Multidimensional no Métrico (NMDS) obtenido (Stress $=0.096)$, muestra una representación espacial en dimensión reducida en función de la similitud de composición florística en 21 parcelas de una hectárea en Madre de Dios (Figura 3). En el NMDS se observó resultados similares al análisis de conglomerados en la diferenciación en la composición florística en función a la distancia geográfica a gran escala y tipo de bosque a escala local.

Por otro lado, a escala local en el NMDS se observó una diferenciación en la composición florística según tipo de bosque (Figura 5). En la Parcelas de MANU, entre las de Bosque de Llanura Inundable (Manu_01, Manu_05 y Manu_06) y de Bosques de Tierra Firme
(Manu_02, Manu_03 y Manu_04). En las parcelas de CUZ, entre las de Bosque Pantano-Estacional (CUZ_04) y las de Bosque de terraza aluvial (CUZ-01, CUZ-02 y CUZ-03).

\section{Discusión}

Las 21 parcelas para el análisis se distribuyeron en cuatro tipos de bosque, Bosque tierra firme (BTF), Bosque llanura inundable (BLLI), Bosque pantano estacional (BPE) y Bosque terraza aluvial (BTA). Asimismo, se evidenció la no existencia de un gradiente altitudinal entre los sitios evaluados. No se ha considerado para el análisis parcelas ubicadas en la provincia de Tahuamanu, por no contar con una base de datos consistente de parcelas de 1 ha. Sin embargo, para la discusión se ha tomado en cuenta las investigaciones realizadas en Alto Purús (Condit et al. 2002; Pitman et al. 2003) y en la localidad de San Lorenzo, Tahuamanu (Dueñas et al. 2009).

En la llanura resaltan las planicies de inundación periódico-estacional por las aguas blan- 


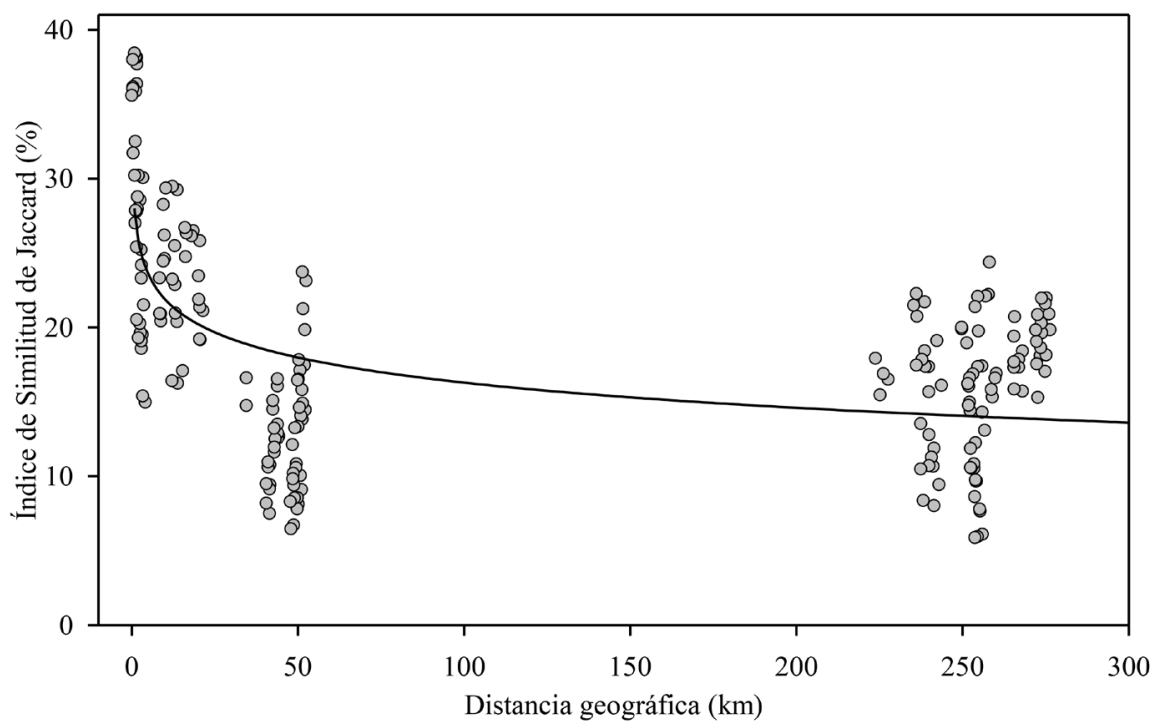

Figura 4. Índice de similitud de Jaccard de la composición florística de parcela de 1 ha de acuerdo a la distancia geográfica.

cas de los grandes ríos que escurren desde los Andes; los pantanos de aguas negras con los aguajales, en aparentes parches pequeños, sin embargo, de gran importancia ecológica; y finalmente las planicies altas depresionadas y en cubetas de las pampas del Heath conformando el complejo de sabanas estacionalmente inundadas (Encarnación et al. 2008).

Como se observa en el Cuadro 1 los rangos en la gradiente altitudinal varían desde 160 a $450 \mathrm{msnm}$, y se considera que la gradiente para Madre de Dios es de 130 msnm (en la frontera con Bolivia) hasta más de $1200 \mathrm{msnm}$, frontera con Puno y Cusco (Encarnación et al. 2008). Las colecciones botánicas se encuentran confinadas desde los $160 \mathrm{msnm}$ hasta los $580 \mathrm{msnm}$, no existiendo inventarios ni colecciones a partir de los $600 \mathrm{msnm}$ hasta los 1200 msnm; lo que sugiere áreas con vacíos de información (Honorio y Reynel 2003) que deberían ser consideradas en estudios próximos, de esta manera el número de registros en especies podría aumentar considerablemente.

En la actualidad, se estima para el departamento de Madre de Dios un total de 1601 es- pecies de árboles (DAP $\geq 10 \mathrm{~cm}$ ), que han sido registrados y se encuentran depositados en los principales herbarios nacionales y extranjeros (Monteagudo com. pers.). Esto es importante porque se corrobora con la presente investigación a través del análisis de la curva de acumulación de especies que arroja 1600 especies para el departamento de Madre de Dios (Figura 2).

\section{De la abundancia y riqueza de especies}

Nuestros resultados son comparativamente altos respecto a los que registraron para el Alto Purús (Pitman et al. 2003); para parcelas de tierra firme de 1 ha con promedios de 574 árboles con DAP de $\geq 10 \mathrm{~cm}$ (con un rango de 510-678 ind/ha).

Los valores de abundancia y riqueza de las 21 parcelas son relativamente similares a otros estudios realizados para la Amazonía (Pitman et al. 2003; Dueñas et al. 2009, 2012; ver Cuadro 3), excepto en parcelas de Yanamono, que cuenta con valores de riqueza de 300 especies/ha, y Allpahuayo con valores de riqueza de 289 especies/ha. Valores de riqueza de especies muy superiores con respecto a los resultados 
del presente estudio en el departamento de Madre de Dios. Lo que sugiere que la riqueza de especies es mayor en el norte de la Amazonía peruana, disminuyendo paulatinamente en el sur de la Amazonía peruana (Gentry 1988), debido a su cercanía a la línea ecuatorial, ocurren altas temperatura, precipitación y humedad y existe una relación directa con la alta diversidad de especies (Yanamono y Mishana); en comparación con las parcelas cercanas a las estribaciones de los andes (Madre de Dios).

Los valores de riqueza de especies de 21 parcelas de 1 ha (Cuadro 3), en tres tipos de bosque para el Departamento de Madre de Dios, son comparativamente iguales o mayores, referente a los resultados reportados en las parcelas de tierra firme del Alto Purús, con un rango de 102 a 158 especies/ha (Gentry 1988). La riqueza de especies disminuye con la respecto a la parcela Tahuamanu con un rango de 86 a 139 especies/ha (Dueñas et al. 2009); y con valores similares o intermedios para parcelas de Rio Amigos, con valores de 126 a 169 especies/ha (Vela 2007), con un promedio de 142 especies/ha, valores iguales o menores que nuestras parcelas; para el caso de la parcela ITA se reportó un rango de (119-135 especies/ha), resultados similares reportados en la parcela Chalalan, del norte de la Amazonia norte-central, con (118 especies/ha) (Silman et al. 2005).

\section{Índice de Shannon-Wiener y $a$-Fisher}

La diversidad de especies de árboles en los trópicos varía dramáticamente de un lugar a otro. Algunas parcelas de 1 ha en América del Sur, contiene casi tantas especies de árboles como los bosques templados húmedos de América del Norte (Latham y Ricklefs 1993; Vasquez y Phillips 2000).

No existen datos del índice de Shannon y a-Fisher para parcelas de Yanamono, Allpahuayo, Chalalán y Alto Purús (Gentry 1988a, 1988b; Silman et al. 2005; Pitman et al. 2003). Sin embargo, se considera que de acuerdo con los datos de abundancia y riqueza de especies; lo valores de éstos índices deben ser muy altos para las parcelas del norte peruano de la Amazonía. Para la parcela de Santa Rosa, los valores de índices de Shannon (4.58) y a-Fisher (90.02) son similares o superiores, respecto a nuestro estudio (Dueñas y Peña 2015). De igual manera para la parcela de Tahuamanu los valores de índices de Shannon (3.89) y $\alpha$-Fisher (50.83) son inferiores con respecto al presente estudio (Dueñas et al. 2009).

La diversidad arbórea de parcelas de una hectárea con ubicación cercana y por lo tanto, bajo las mismas condiciones climáticas, pueden presentar grandes diferencias en la diversidad de especies arbóreas (Valencia et al. 2004; ter Steege et al. 2003). Otros bosques son menos diversos que las parcelas equivalentes en bosques templados. Incluso dentro de la cuenca del Amazonas, el índice de alfa de Fisher de árboles en parcelas de 1 ha varía entre 222 a 6 (ter Steege et al. 2003).

\section{De la Composición Florística}

La comparación de la composición florística de 21 parcelas de 1 ha en tres tipos de bosque para el Departamento de Madre de Dios, con otros estudios en la Amazonía peruana; nuestros valores reportados para composición florística son similares (comparten un 50\% de especies) a los reportados por Pitman et al. (2003), para parcelas de 1 ha en el Alto Purús. Mientras que los reportados para la localidad de Santa Rosa, Inambari y Tahuamanu por Dueñas et al. (2009) y Dueñas y Peña (2015), para parcelas de 1 ha son relativamente similares en su composición florística (Cuadro 6).

\section{Índice de Importancia}

Nuestros datos se corroboran con los de ter Steege et al. (2013), en cuanto se refiere a valores máximos de abundancia de árboles en la Amazonía, especies compartidas con el presente estudio son Euterpe precatoria, Pseudolmedia laevis, Iriartea deltoidea, Astrocaryum murumuru y Rinorea guianensis como las especies hiperdominantes en Madre de Dios.

Según el estudio de Fauset et al. (2015), referido a las 20 especies más dominantes de árboles de la Amazonía, encontramos por lo 


\begin{tabular}{lcccc}
\hline \multicolumn{1}{c}{ Parcelas } & Altitud & Familias & Géneros & Especies \\
\hline CHONTA-IIAP* & 190 & 38.5 & 99.5 & $153.5(134-174)$ \\
CUZ** & 190 & 42.25 & 95.75 & $138.5(130-157)$ \\
TAMB** & 211 & 42.29 & 103.71 & $168.71(142-191)$ \\
MANU*** & 348 & 44.17 & 108.17 & $161.66(147-197)$ \\
ITA**** & 160 & 34 & 83 & $127(119-135)$ \\
Yanamono***** & 140 & - & - & 289 \\
Allpahuayo***** & 150 & - & - & 300 \\
Chalalan+ & 400 & 43 & - & 118 \\
Santa Rosa++ & $220-500$ & 40 & 99 & 174 \\
Alto Purús+++ & 298 & 59 & 196 & $434(102-158)$ \\
Tahuamanu++++ & 260 & 67 & 93 & $115(86-106)$ \\
\hline
\end{tabular}

Cuadro 6. Comparación Composición Florística. Parcelas Chonta-IIAP* (Baéz y Oblitas 2015, Cueva 2015), Parcelas RAINFOR ${ }^{\star \star}$ (ForestNet.Plot 2015), Parcelas TEAM*** (Data Team 2015), Parcelas ITA $^{* * * *}$ (Dueñas et al. 2012), Parcelas Norte peruano***** (Gentry 1988a, 1988b), Parcelas Norte Boliviano+ (Silman et al. 2005), Parcelas Santa Rosa++ (Dueñas y Peña 2015), Parcelas Alto Purus+++ (Pitman et al. 2003), Parcelas Tahuamanu++++ (Dueñas et al. 2009).

menos 3 especies compartidas con el presente estudio, Bertholletia excelsa, Iriartea deltoidea y Pseudolmedia laevis; que son las especies hiperdominantes en toda la Amazonía.

El grupo de especies con el menor índice de importancia (especies raras o poco frecuentes, Cuadro 5), son de mucha importancia, porque éstas podrían ser más vulnerables a impactos antropogénicos (tala, agricultura, minería, cambio climático, etc.) debido a sus bajas densidades poblacionales. Estas especies serían clave para programas de manejo y conservación de los bosques tropicales (Moreno 2001).

\section{Análisis Multivariado}

Los resultados de las 21 parcelas de 1 ha según el índice de importancia según conglomerado, son similares y se corroboran con otras investigaciones para parcelas de 1 ha y en diferentes tipos de bosques en Madre de Dios (Pallqui 2013; Baez y Oblitas 2017; Dueñas et al. 2009).

El NMDS muestra grupos definidos en función a la distancia geográfica (Figura 3), definida por las elipses (MANU, CUZ y TAM).
Las parcelas de CUZ presentaron un mejor agrupamiento, a diferencia de las parcelas de MANU que estuvieron menos agrupadas en la representación en dimensión reducida. Asimismo, se observa una afinidad florística entre las parcelas de CHONTA, IIAP y TAM, debido a que son parcelas localizadas en bosque de tierra firme. La cercanía en el NMDS entre las parcelas de CUZ e ITA se justifica debido a su cercanía geográfica $(9 \mathrm{~km})$ y que corresponden a un similar tipo de bosque, Bosque de terraza aluvial (Figura 5).

Implicancias futuras de la diversidad, dominancia y composición florística de Madre de Dios

Implicancia directa, actualmente, en Madre de Dios nos encontramos en un escenario incierto, debido principalmente a la influencias de actividades antropogénicas (megaproyectos, carreteras, minería, deforestación y agricultura). El futuro es incierto, diversidad, dominancia, composición florística y distribución de las especies vienen siendo afectadas dentro de este contexto. 


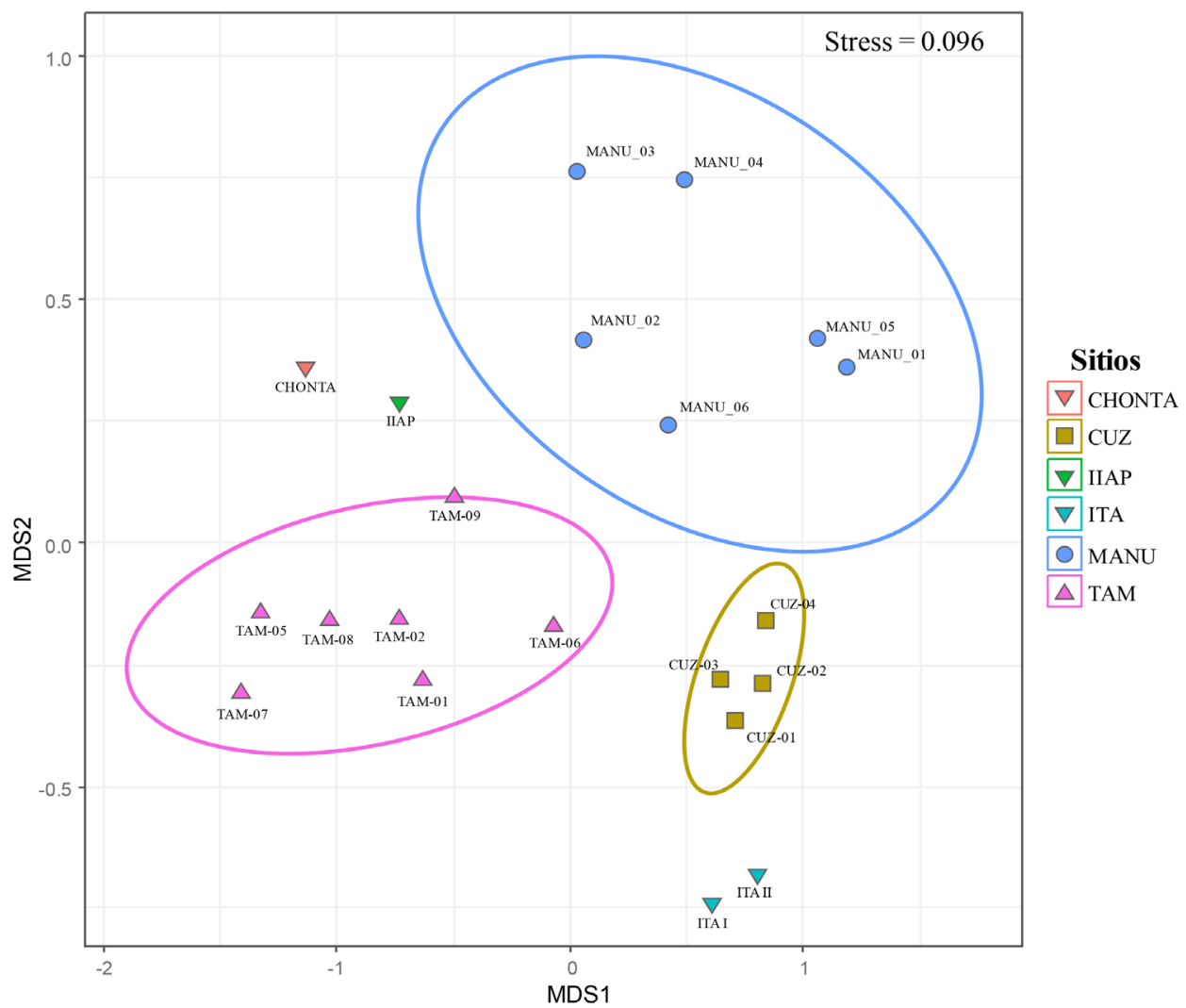

Figura 5. Distribución de las parcelas evaluadas (composición florística) en dimensión reducida utilizando un Análisis Multidimensional no Métrico (NMDS, matriz de disimilitud de Jaccard). Las elipses indican los intervalos de confianza de $90 \%$ alrededor de los centroides de tres sitios estudiados. BLLI=Bosque llanura inundable, $\mathrm{BPE}=$ Bosque pantano estacional.

Indirecta, el cambio climático a mediano y largo plazo a nivel regional, sería un de los factores más relevantes que podría influir en la diversidad, dominancia, composición florística y distribución.

\section{Conclusiones}

Los valores de diversidad y dominancia de especies en las parcelas evaluadas son superiores en comparación con otros sitios en la región Madre de Dios (Alto Purús, Tahuamanu, Río Los Amigos e Inambari) e inferiores a los registrados en la región Loreto (Mishana y Yanamono). En el presente estudio, las áreas evaluadas están distribuidos en cuatro tipos de bosques: bosque tierra firme, llanura inundable, pantano estacional y terraza aluvial (Encarnación et al. 2008).

El patrón de riqueza y diversidad arbórea se puede observar según la ubicación y el tipo de bosque de las parcelas, de hecho, las parcelas en bosques de tierra firme tienden a tener los valores más altos en comparación con las parcelas de bajío, aguajales o estacionalmente inundable, que presentan valores más bajos aún. Además, de acuerdo a la ubicación de las parcelas: las más cercanas a las estribaciones de los andes como el río Manu y río 

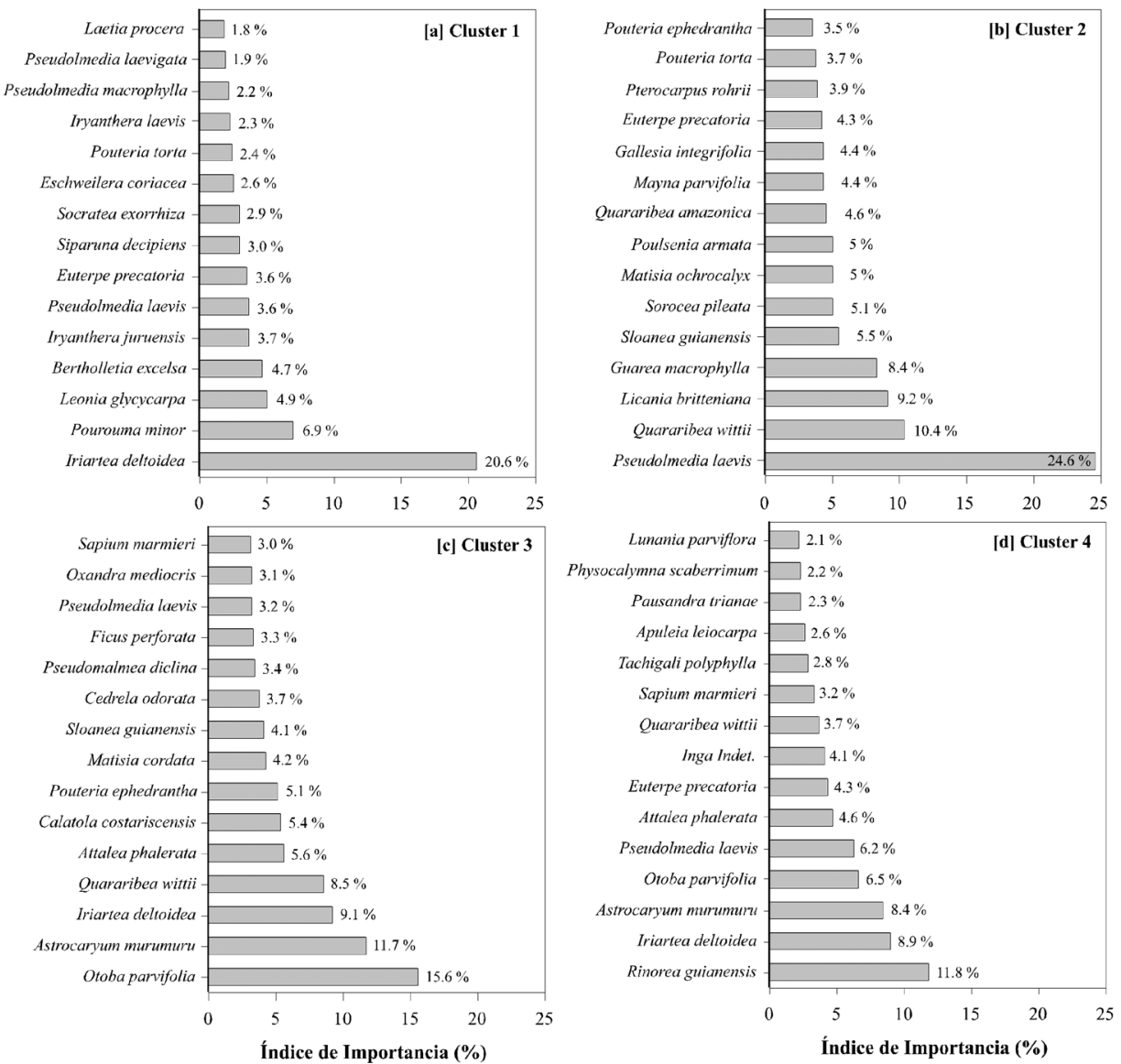

Figura 6. Índice de importancia de especies más importantes según conglomerado jerárquico.

Tambopata van a ser más ricos y con valores altos de diversidad (debido a que son bosques más húmedos), respecto a los del río Madre de Dios y más bajos aun en comparación a los que se encuentran cercanas al río Heath (hacia Bolivia). Por lo tanto, en la región Madre de Dios se observa un patrón de mayor diversidad al Nor-Oeste (parcelas Manu) y menor diversidad hacia el Sur-Este (parcelas ITA y Cuzco Amazónico).

Los análisis multivariados, conglomerados y NMDS, sugieren una diferenciación en la composición florística en función a la distancia geográfica a gran escala (nivel regional). Sin embargo, a escala local, se encontró una diferenciación en la composición florística según tipo de bosque.

La composición florística encontrada es similar a otros sitios en la región Madre de Dios (Alto Purús, Tahuamanu, Río Los Amigos), las cuales comparten un elevado número de familias, géneros y especies.

\section{Agradecimientosos}

A la Universidad Nacional Mayor de San Marcos, a través del Programa de Doctorado en Ciencias Biológicas. A mis mentores Dra. Betty Millán y al Dr. Carlos Reynel por su 
apoyo y aporte en todas las etapas de la investigación. Al Herbario de San Marcos (USM), al Centro de Investigación Herbario "Alwyn Gentry”-UNAMAD. A Gabriela López y Oliver Phillips por su disposición y apoyo con la Base de Datos de Forest.Plot; y por sus sugerencias en la revisión del manuscrito. A Patricia Álvarez de TEAM por proporcionarnos la base de las parcelas Manu; Abel Monteagudo, Tim Baker y Rodolfo Vásquez por sus valiosos aportes y sugerencias sobre el manuscrito. A Sufer Báez, Oliver Surco, Dante Cueva, Jaime Oblitas por los datos de campo y su apoyo. A Cienciactiva CONCYTEC, a través del Círculo de Estudios DINAFOR (UNALM), por su apoyo valioso en el financiamiento en la última etapa de esta investigación.

\section{Bibliografía}

APG IV, (Angiosperm Phylogeny Group); Chase, MW; Christenhusz, MJM; Fay, MF; Byng, JW; Judd, WS; Soltis, DE; Mabberley, DJ; Sennikov, AN; Soltis, PS; Stevens, PF; Briggs, B; Brockington, S; Chautems, A; Clark, JC; Conran, J; Haston, E; Möller, M; Moore, M; Olmstead, R; Perret, M; Skog, L; Smith, J; Tank, D; Vorontsova, M; Weber, A. 2016. An update of the Angiosperm Phylogeny Group classification for the orders and families of flowering plants: APG IV. Botanical Journal of the Linnean Society 181(1):1-20. DOI: https://doi. org/10.1111/boj.12385.

Araujo-Murakami, A; Parada, A; Terán, J; Baker, T; Feldpausch, TR; Phillips, OL; Brienen, RJW. 2011. Necromasa de los bosques de Madre de Dios, Perú ; una comparación entre bosques de tierra firme y de bajíos. Rev. peru. biol. 18(1):113-118.

Baez, S; Oblitas, J. 2017. Diversidad arbórea y estructura en un bosque de tierra firme del sector Unión Chonta, distrito Tambopata - región Madre de Dios. Mentor Forestal 1:24-28.

Borcard, D; Gillet, F; Legendre, P. 2009. Numerical Ecology with R. New York (USA), Springer Science. 2011 p. DOI: https://doi. org/10.1007/978-0-387-78171-6.
Boyle, B; Hopkins, N; Lu, Z; Raygoza Garay, JA; Mozzherin, D; Rees, T; Matasci, N; Narro, ML; Piel, WH; Mckay, SJ; Lowry, S; Freeland, C; Peet, RK; Enquist, BJ. 2013. The taxonomic name resolution service: an online tool for automated standardization of plant names (en línea). BMC Bioinformatics 14(1):16. DOI: https://doi.org/10.1186/1471-2105-14-16.

Colwell, RK. 2013. EstimateS: statistical estimation of species richness and shared species from samples. s.l., s.e., vol.Version 9.

Condit, R; Pitman, N; Leigh, EG; Chave, J; Terborgh, J; Foster, RB; Núñez, P; Aguilar, S; Valencia, R; Villa, G; Muller-Landau, HC; Losos, E; Hubbell, SP. 2002. Beta-Diversity in Tropical Forest Trees (en línea). Science 295(5555):666669. DOI: https://doi.org/10.1126/science. 1066854 .

Cueva, A. 2015. Caracterización Dendrológica en 1 ha de bosque de terraza alta, localidad de Fitzcarrald km 21,5 Distrito de Tambopata, Provincia de Tambopata - Madre de Dios. s.l., Universidad Nacional Amazónica de Madre de Dios.

Curtis, J; McIntosh, R. 1951. An upland forest continuum in the prairie-forest border region of Wisconsin (en línea). Ecology 32(3):476496. DOI: https://doi.org/10.2307/1931725.

Dueñas, H; Nieto, C; Florez, J; Soto, M; Gutiérrez, E; Del Alcazar, J; Bejar, N; Baez, S; Casanova, P; Collazos, B; Cuenca, L. 2009. Diversidad y Composición florística en la localidad de San Lorenzo: Provincia de Tahuamanu. Biodiversidad Amazónica 2:71-82.

Dueñas, H; Nieto, C; Peña, J; Kuaquira, F. 2012. Diversidad, Composición Florística y Stock de Carbono almacenado en la Biomasa de dos hectáreas de Bosque Húmedo Tropical en la Reserva Ecológica de Inkaterra, Tambopata - Madre de Dios. s.l., Universidad Nacional Amazónica de Madre de Dios (UNAMAD). .

Dueñas, H; Peña, J. 2015. Diversidad, Dominancia y Composición florística de árboles en los bosques de la localidad de Santa Rosa; distrito de Inambari, Provincia de Tambopata, Madre de Dios. Floresta Amazónica 1:51-64. 
Encarnación, F; Zarate, R; Ahuite, M. 2008. Zonificación Ecológica y Económica del Departamento de Madre de Dios - Temática Vegetación. Puerto Maldonado (Perú), GOREMAD-IIAP.

Erwin, T. 1984. Tambopata Reserved Zone, Madre de Dios, Perú: History and description of the Reserve. Revista Peruana de Entomología 27:1-8.

Eva, H; Huber, O; Achard, F; Balslev, H; Beck, S; Behling, H; Belward, A; Beuchle, R; Cleef, A; Colchester, M; Duivenvoorden; Hoogmoed, M; Junk, W; Kabat, P; B. Kruijit; Malhi, Y; Müller, JM; Pereira, JM; Peres, C; Prance, GT; Roberts, J; Salo, J. 2005. A proposal for defining the geographical boundaries of Amazonia. Eva, $\mathrm{H}$; Huber, $\mathrm{O}$ (eds.). Ispra, Amazon Cooperation Treaty Organization. 1-40 p. DOI: https:// doi.org/ISBN 9279000128.

Fauset, S; Johnson, MO; Gloor, M; Baker, TR; Monteagudo, A; Brienen, RJW; Feldpausch, TR; Lopez-Gonzalez, G; Malhi, Y; ter Steege, H; Pitman, NCA; Baraloto, C; Engel, J; Pétronelli, P; Andrade, A; Camargo, JLC; Laurance, SGW; Laurance, WF; Chave, J; Allie, E; Vargas, PN; Terborgh, JW; Ruokolainen, K; Silveira, M; Aymard, GA; Arroyo, L; Bonal, D; Ramirez-Angulo, H; Araujo-Murakami, A; Neill, D; Hérault, B; Dourdain, A; Torres-Lezama, A; Marimon, BS; Salomão, RP; Comiskey, JA; Réjou-Méchain, M; Toledo, M; Licona, JC; Alarcón, A; Prieto, A; Rudas, A; van der Meer, PJ; Killeen, TJ; Marimon Junior, B; Poorter, L; Boot, RGA; Stergios, B; Torre, E V.; Costa, FRC; Levis, C; Schietti, J; Souza, P; Groot, N; Arets, E; Moscoso, VC; Castro, W; Coronado, ENH; Peña-Claros, M; Stahl, C; Barroso, J; Talbot, J; Vieira, ICG; van der Heijden, G; Thomas, R; Vos, VA; Almeida, EC; Alvarez-Davila, E; Aragão, LEOC; Erwin, TL; Morandi, PS; de Oliveira, EA; Valadão, MBX; Zagt, RJ; van der Hout, P; Loayza, PA; Pipoly, JJ; Wang, O; Alexiades, M; Cerón, CE; Huamantupa-Chuquimaco, I; Di Fiore, A; Peacock, J; Camacho, NCP; Umetsu, RK; de Camargo, PB; Burnham, RJ; Herrera, R; Quesada, CA; Stropp, J; Vieira,
SA; Steininger, M; Rodríguez, CR; Restrepo, Z; Muelbert, AE; Lewis, SL; Pickavance, GC; Phillips, OL. 2015. Hyperdominance in Amazonian forest carbon cycling. (en línea). Nature communications 6: 6857. DOI: https://doi. org/10.1038/ncomms7857.

Gentry, AH. 1988a. Changes in Plant Community Diversity and Floristic Composition on Environmental and Geographical Gradients. Annals of the Missouri Botanical Garden 75(1):1. DOI: https://doi.org/10.2307/2399464.

Gentry, AH. 1988b. Tree species richness of upper Amazonian forests. Proceedings of the National Academy of Sciences 85(1):156-159. DOI: https://doi.org/10.1073/pnas.85.1.156.

Hammer, Ø; Harper, D a T. 2006. Paleontological Data Analysis. 1st edition. Oxford, Blackwell Publishing. 351 p. DOI: https://doi. org/10.1002/9780470750711.

Honorio, E; Reynel, C. 2003. Vacíos en la colección de la flora de los bosques húmedos del Perú. Lima, Universidad Nacional Agraria la Molina. 75 p.

Kindt, R; Coe, R. 2005. Tree Diversity Analysis. A Manual and Software for Common Statistical Methods for Ecological and Biodiversity Studies. World Agroforestry Centre (ICRAF).

Lamas, G. 1994. List of Butterflies from Tambopata (Explorer's Inn Reserve). In Barkley L. (ed.). Washington D.C., Conservation International. p. 162-177.

Latham, RE; Ricklefs, RE. 1993. Continental Comparisons of Temperate-Zone Tree Species Diversity. Species Diversity in Ecological Communities: Historical and Geographical Perspectives :294-314.

Li, W; Fu, R; Dickinson, RE. 2006. Rainfall and its seasonality over the Amazon in the 21 st century as assessed by the coupled models for the IPCC AR4. Journal of Geophysical Research Atmospheres 111(2):1-14. DOI: https:// doi.org/10.1029/2005JD006355.

Lozada, J. 2010. Consideraciones metodológicas sobre los estudios de comunidades forestales. Revista Forestal Venezolana 54(1):77-88. 
Oksanen, J; Blanchet, G; Friendly, M; Kindt, R; Legendre, P; Mcglinn, D; Minchin, PR; Hara, RBO; Simpson, GL; Solymos, P; Stevens, MHH; Szoecs, E; Wagner, H. 2017. vegan: Community Ecology Package. R package version 2.4-3 (en línea). s.l., s.e. Disponible en https://cran.r-project.org/package=vegan.

Pallqui, N. 2013. Dinámica de un bosque tropical: biomasa aérea y análisis en parcelas permanentes a largo plazo, Reserva Nacional Tambopata - Madre de Dios. s.l., Universidad Nacional San Antonio Abad del Cusco (UNSAAC). .

Parker, TA; Donahue, P; Schulenberg. 1994. Birds of the Tambopata Reserve. In Foster, JC\& AF (ed.). Washington D.C., Conservation International.

Pearson, DL. 1984. The tiger beetles (Coleoptera: Cicindelidae) of the Tambopata reserved zone, Madre de Dios, Peru. Revista Peruana de Entomologia 27:15-24.

Phillips, OL; Martínez, RV; Vargas, PN; Monteagudo, AL; Zans, MEC; Sánchez, WG; Cruz, AP; Timaná, M; Yli-Halla, M; Rose, S. 2003. Efficient plot-based floristic assessment of tropical forests. Journal of Tropical Ecology 19(6):629-645. DOI: https://doi.org/10.1017/ $\underline{\mathrm{S} 0266467403006035}$.

Pitman, NCA; Terborgh, J; Nuñez, P; Valenzuela, M. 2003. Los árboles de la cuenca del Río Alto Purús. In Pitman, NCA; Alvarez, P (eds.). Lima, Perú, . Center for Tropical Conservation, Duke University. p. 53-61.

Pitman, NCA; Terborgh, J; Silman, MR; Nuñez V., P. 1999. Tree species distributions in an upper amazonian forest. Ecology 80(8):26512661. DOI: https://doi.org/10.1890/0012-965 8(1999)080[2651:TSDIAU]2.0.CO;2.

Pitman, NCA; Terborgh, JW; Silman, MR; Núñez, P V.; Neill, DA; Cerón, CE; Palacios, WA; Aulestia, M. 2001. Dominance and distribution of tree species in upper Amazonian terra firme forests. Ecology 82(8):2101-2117. DOI: https://doi. org/10.1890/0012-9658(2001)082[2101:DADOTS]2.0.CO;2.
Quesada, CA; Lloyd, J; Anderson, LO; Fyllas, NM; Schwarz, M; Czimczik, CI. 2011. Soils of Amazonia with particular reference to the RAINFOR sites. Biogeosciences 8(6):14151440. DOI: https://doi.org/10.5194/bg-8-14152011.

R Core Team. 2016. R: A language and environment for statistical computing (en línea). Vienna, Austria: R Foundation for Statistical Computing, s.e. Disponible en https://www.r-project.org/.

Silman, M; Araujo-Murakami, A; H.Urrego, D; Bush, MB; Pariamo, H. 2005. Estructura de las comunidades de árboles en el límite sur de la Amazonía occidental: Manu y Madidi. Ecología en Bolivia 40(3):443-452.

Ter Steege, H; Pitman, N; Sabatier, D; Castellanos, H; Van Der Hout, P; Daly, DC; Silveira, M; Phillips, O; Vasquez, R; Van Andel, T; Duivenvoorden, J; De Oliveira, AA; Ek, R; Lilwah, R; Thomas, R; Van Essen, J; Baider, C; Maas, P; Mori, S; Terborgh, J; Vargas, PN; Mogollón, H; Morawetz, W. 2003. A spatial model of tree $a$-diversity and tree density for the Amazon. Biodiversity and Conservation 12(11):2255-2277. DOI: https://doi. org/10.1023/A:1024593414624.

Tuomisto, H; Ruokolainen, K; Kalliola, R; Linna, A; Danjoy, W; Rodriguez, Z. 1995. Dissecting Amazonian Biodiversity. Source: Science, New Series 269(5220):63-66. DOI: https://doi. org/10.1126/science.269.5220.63.

Valencia, R; Foster, RB; Villa, G; Condit, R; Svenning, JC; Hernández, C; Romoleroux, K; Losos, E; Magård, E; Balslev, H. 2004. Tree species distributions and local habitat variation in the Amazon: Large forest plot in eastern Ecuador. Journal of Ecology 92(2):214-229. DOI: https:// doi.org/10.1111/j.0022-0477.2004.00876.x.

Vasquez, R; Phillips, O. 2000. Allpahuayo: Floristics, structure, and dynamics of a high- diversity forest in Amazonian Peru. Annals of the Missouri Botanical Garden 87(4):499-527.

Vela, C. 2007. Estructura y composición florística del llano inundable. s.l., Universidad San Antonio Abad del Cusco. 55 p. 
Wickham, H. 2015. ggplot2 Elegant Graphics for Data Analysis.

Presentado: $18 / 03 / 2018$

Aceptado: 24/05/2018 